\title{
Detecting Depth and Lateral Spread of Roots of Native Range Plants Using Radioactive Phosphorus
}

\author{
PAT O. CURRIE AND FREDERICK L. HAMMER
}

\section{Abstract}

Radioactive phosphorus $\left(\mathrm{P}^{32}\right)$ was used to measure root depth and lateral spread of four native plant species which had been subjected to heavy grazing for many years. Compared with root excavation measurements from an earlier study on the same area, rooting depths of all species tested were found to be quite similar by the two methods. Lateral spread differed substantially, however. Roots were found to have a greater lateral spread by the $P^{32}$ estimate. The isotope method using autoradiography was found to be a sensitive method of determining depth and lateral spread of in situ plant roots in a mixed plant community.

A number of investigators have used radioactive phosphorus, $\mathbf{P}^{32}$, to determine plant rooting characteristics (Aebersold 1953). Mathis et al. (1965) evaluated growth, activity, and varietal differences in cotton, corn, peanuts and tobacco roots using a tracer technique. Root growth of sorghums was measured by McClure and Harvey (1962) by use of radioactive phosphorus. Nye and Foster (1961) in Ghana determined the relative uptake and use of several short-term annual and perennial plants from various root zones using labelled $\mathrm{P}^{32}$. Boggie et al. (1958) in Scotland use radioactive tracers to investigate plant root systems growing in peat and mineral soils. The methodology was found very useful in both soil types, and they suggested that $\mathrm{P}^{32}$ could be used to determine maximum rooting depth of each species composing a community. They also suggested it could be adapted for determining lateral spread of root systems. Their work was based on placement of $\mathrm{P}^{32}$ at different levels within the soil of four different grassland communities and measuring the specific activity of $\mathrm{P}^{32}$ uptake by each species. A modification of this technique was used in the present study to determine depth and lateral spread of roots of four major species in the ponderosa pine-bunchgrass type of Colorado. Results are compared with those for a root excavation technique used by Schuster (1964) from a study made on the same heavily grazed experimental sites.

\section{Study Area}

The work was conducted at the Manitou Experimental Forest $45 \mathrm{~km}$ northwest of Colorado Springs, Colo., at approximately $2,375 \mathrm{~m}$ elevation. Annual precipitation in this area averages about $400 \mathrm{~mm}$

Authors are prıncıpal range scientist and range technician (retired), Rocky Mountain Forest and Range Lxperiment Station, U.S. Department of Agriculture, Forest Service, with central headquarters maintained in cooperation with Colorado State University, Fort Collıns rUS 21. Present address for Dr. Currie is Science and Education AdministrationAgriculture Research, Livestock and Range Research Station, Route 1, Box 3, Miles City, Montana $5 y 301$. Mr. Hammer's address is SR1, Box 71\%, Belen, New Mexico 87002. Keprints may be requested from the Director, Rocky Mountain Forest and Range Experiment Station, Fort Collins, Colorado 80521

Manuscript received March 23, 1978. with nearly three-fourths occurring during the spring and summer growing season, from April through August. Soils are derived from Pikes Peak granite and they are a sandy loam or sandy clay loam with low fertility and moderate amounts of organic matter. These soils are porous when wet but very hard when dry.

Vegetation is characteristic of the ponderosa pine-bunchgrass type of the central and southern Rocky Mountains. It is characterized by a complex of plant communities with open grassland parks interspersed among irregular stands of pondeosa pine (Currie 1975). The most important forage species are Arizona fescue (Festuca arizonica Vasey) and mountain muhly (Muhlenbergia montana (Nutt.) Hitchc.). Other abundant species include fringed sagebrush (Artemisia frigida Willd.), blue grama (Bouteloua gracilis (H.B.K.) Lag.), pussytoes (Antennaria spp.), and sedges (Carex spp.).

Arizona fescue and mountain muhly produce the most forage and cover on ungrazed areas, but both are reduced by continued, season-

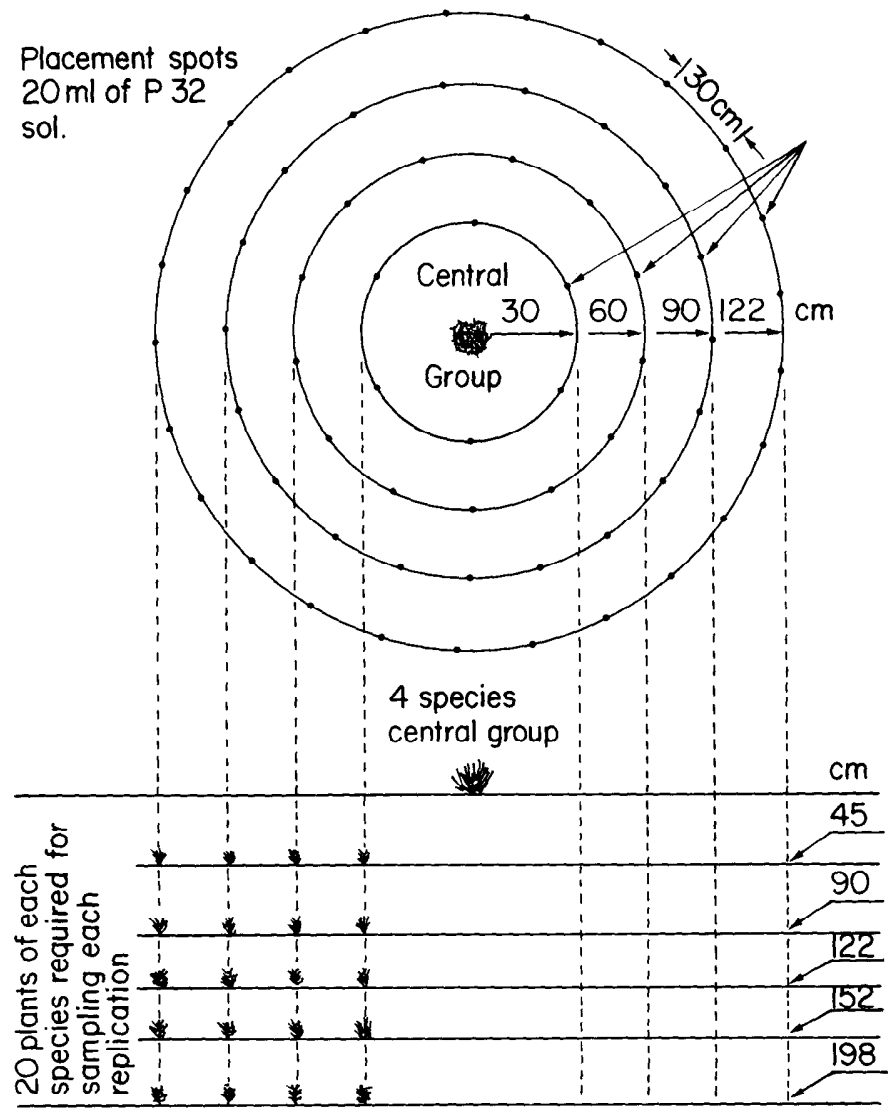

Fig. 1. Schematic diagram of drill hole arrangement for placement of $P^{32}$ Holes were drilled to one specific depth and concentric circle size around a closely associated grouping of four plant species at each site. 
long grazing. The less desirable blue grama and fringed sagebrush become more abundant on heavily grazed ranges. The pastures used in this study had been grazed heavily since 1941. Effects of this grazing treatment on plants and animals are discussed in detail by Smith (1967). Specifically, pasture 1 described in this earlier research was used as the site for the present study.

\section{Study Methods}

Root study locations were confined to the open grasslands away from the direct influence of ponderosa pine. Each site selected had four species, Arizona fescue, mountain muhly, blue grama, and fringed sagebrush, growing in very close proximity to one another, usually within an area of $15 \times 15 \mathrm{~cm}$. Three replications were established, and each replication included 20 sites. Each site had holes drilled around the central plants at one of five depths and four lateral distances out from the plant grouping (Fig. 1). Thus, 240 plants, or 20 of each species in each replication, were required to sample all depths and lateral distances. For any given depth and distance, 4-cm diameter holes were drilled at $30-\mathrm{cm}$ intervals surrounding the central plant grouping. Placement access holes were drilled into the soil using a pickup mounted, commercial soil auger. Soil was saved and replaced in each hole following the isotope placement.

Isotope material was injected using the continuous pipetting instrument described by Loewenstein (1965). Treble superphosphate in water was used as the carrier, and $20 \mathrm{ml}$ of $\mathrm{P}^{32}$ solution was injected in each placement hole. The labelled $\mathrm{P}^{32}$ used was potassium dihydrogen phosphate $\left(\mathrm{KH}_{2} \mathrm{P}^{32} \mathrm{O}_{4}\right)$. It had a specific activity of 0.003 millicuries $(.003 \mathrm{mc})$ per $\mathrm{ml}$.

Care was exercised in lowering and lifting the probe to avoid touching the sides and contaminating soils above the desired placement levels. The probe was always moved outside the ring of placement holes to avoid an accidental drip onto plants to be monitored. An additional one-way Luer-Lok ${ }^{1}$ connector was installed below the syringe and above the injection probe described by Loewenstein (1965). This safety feature did not permit leakage during movement from hole to hole. Also, the syringe was kept in an upright position when being moved to avoid any dripping and contamination.

Starting 12 days after the initial injection, plant crowns and leaves were monitored with an end window Geiger-Muller (G.M.) ${ }^{1}$ counter to determine if $\mathrm{P}^{32}$ was being translocated. Because some roots might have been cut by hole drilling, monitoring with the G.M. counter was continued for several of the 14.3-day half-lives of $\mathrm{P}^{32}$. It was assumed that new roots could move into the phosphorus banded zone, and this activity could be detected if the $\mathrm{P}^{32}$ activity remained sufficiently high. In this interim period, additional radioactivity tests on aboveground parts were made using autoradiography on nonscreen x-ray film. A few leaves, culms, or stems of each species were clipped to crown level. These samples were placed on sealed individual packets of x-ray film and allowed to expose in the laboratory for 12 hours. The film was then developed to determine if photons from the radioactive phosphorus had exposed the film.

\section{Results and Discussion}

Autoradiography was found to be much more sensitive than field monitoring using a G.M. counter. As shown in Figure 2, Arizona fescue readily exposed the $\mathrm{x}$-ray film, and the amount of plant material and radioactivity, except for illustrative purposes, was in excess of that needed for analytical comparisons. Autoradiography also avoided the problem of detecting radioactivity from more than one plant species in the mixed community, as was encountered in using the G.M. counter. Individual species and plant parts from all portions of the crown

I he use of trade names in this publication is for the information and convenience of the reader and does not constitute an official endorsement or approval of any product or service by the U.S. Department of Agriculture to the exclusion of others which may be sultable.
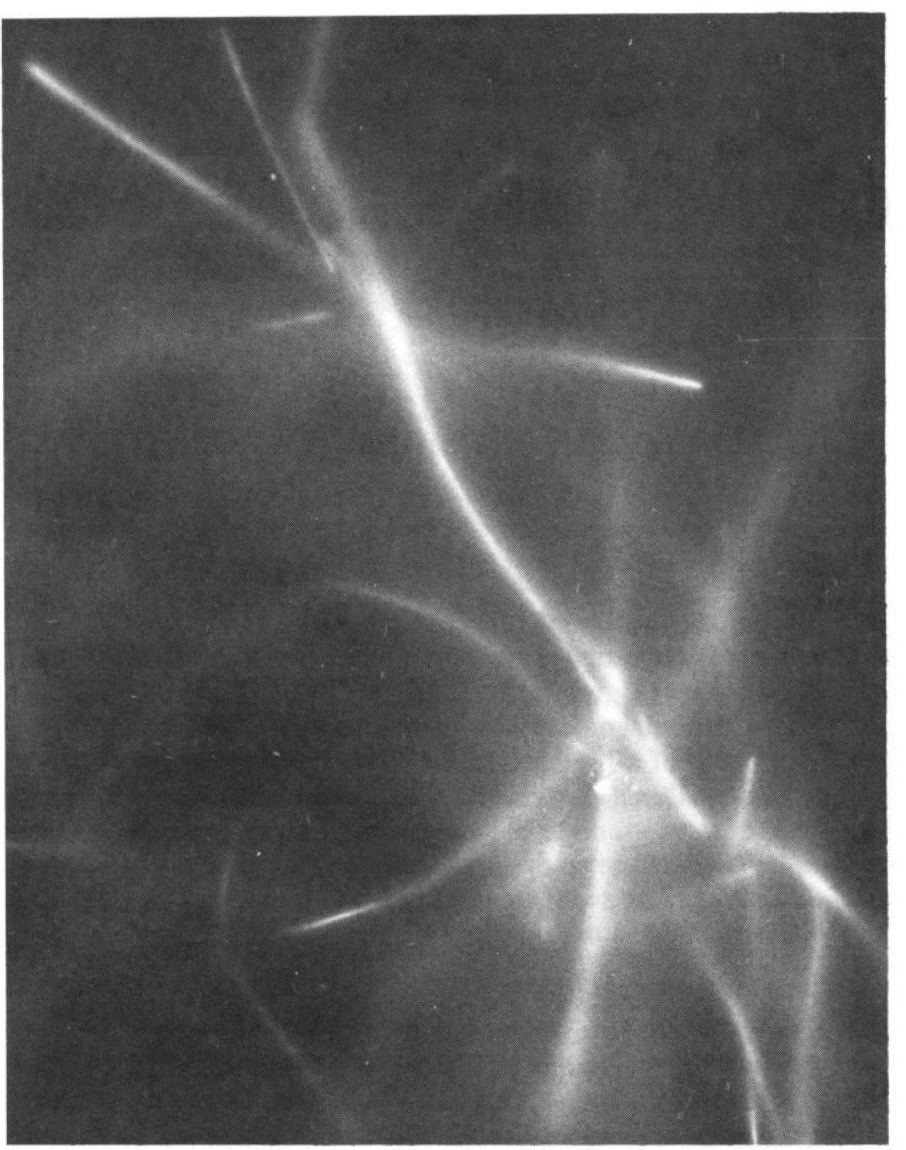

Fig. 2. Autoradiograph of Arizona fescue leaves and stems following translocation from roots. This method of radioisotope detection was found very useful and sensitive for evaluating depth and lateral spread of roots following translocation to aboveground parts. Aerial parts shown were from a site where $P^{32}$ was injected to $46 \mathrm{~cm}$ deep and $30 \mathrm{~cm}$ out from the central grouping.

could be readily sampled and monitored for the translocation of the $\mathrm{P}^{3: 2}$. Thus, the problem of some roots picking up the phosphorus and translocating it to only one part of the crown or leaves in very small amounts did not occur, since samples were analyzed from all portions of each plant. Very small amounts of radiation, which only slightly exceeded background on a G.M. counter, also were readily detected.

All four species-Arizona fescue, mountain muhly, blue

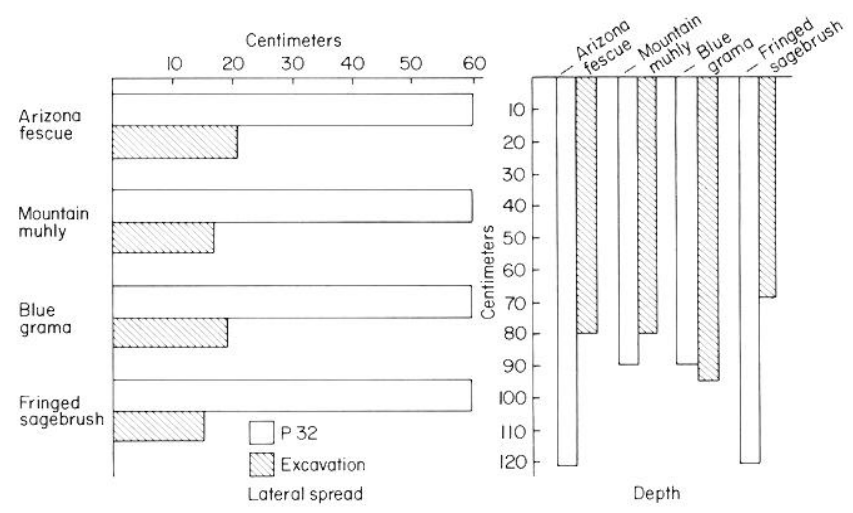

Fig. 3. Average lateral spread and average root penetration of four plant species on a heavily grazed range as measured with radioactive phosphorous and by the root excavation technique. (Adapted from Schuster 1964.) 
grama, and fringed sagebrush-had rooting depths and lateral root distributions which were quite similar and did not differ significantly. The maximum depth of penetration generally did not exceed $90 \mathrm{~cm}$ except for one individual plant of Arizona fescue and one fringed sagebrush. These two plants each reached a depth of $122 \mathrm{~cm}$. These results on depth of rooting were quite similar to those of Schuster (1964) using the excavation technique (Fig. 3). The depths of penetration were also similar to those for a different species of fescue and other species growing on sand and sandy-loam soils reported by Boggie et al. (1958) in Scotland.

The lateral spread of roots, however, differed substantially from those determined by Schuster (1964) (Fig. 3). Roots of Arizona fescue, mountain muhly, blue grama, and fringed sagebrush were found to extend outward to about $60 \mathrm{~cm}$ by the isotope tracer technique. Occasionally, lateral spread reached only $30 \mathrm{~cm}$ for each of the four species, but at least one plant of each species had roots extending to the $60-\mathrm{cm}$ lateral distance. These distances were somewhat less but more closely approximated lateral spread reported by Mathis et al. (1965) for plains bristlegrass. They reported a lateral spread of $76 \mathrm{~cm}$ for plants which had been clipped and about $100 \mathrm{~cm}$ for plants on unclipped plots.

The difference in measured lateral spread between the excavated and isotope monitored roots could be caused by several factors. The same plants and their root distributions were not measured during the same years or for exact comparative purposes in the two studies. Only one plane and a profile of usually less than $20 \mathrm{~cm}$ in thickness was sampled by the excavation-washing technique. Small segments of roots may have been cut off or lost in washing by the excavation technique; whereas, comparable roots remained intact or grew where the isotope injection method was used. Other factors which gave an advantage to using isotope methodology included sampling from all planes within the soil in relation to individual plant crowns. The sample size for individual species was larger, which increased the opportunity to sample plants with greater root spread. This in situ method was nondestructive, which permitted sampling species in a competitive situation with root systems fully intact.

\section{Literature Cited}

Aebersold, P.C. 1953. Survey of present uses of isotopes in agriculture. A conference on the use of isotopes in plant and animal research. Kansas State Coll., U.S. A.E.C. Pub. No. TLD-5098, 26 p. U.S. Government Print. Off., Washington, D.C.

Boggie, R., R.F. Hunter, and A.H. Knight. 1958. Studies of the root development of plants in the field using radioactive tracers. J. Ecol. 46(3):621-639.

Currie, P.O. 1975. Grazing management of ponderosa pine-bunchgrass ranges of the central Rocky Mountains. The status of our knowledge. U.S. Dep. Agr. Forest Serv. Res. Pap. RM-159, 24 p. Rocky Mt. Forest and Range Exp. Sta., Fort Collins. Colo.

Loewenstein, H. 1965. An injection probe for rapid placement of radioisotopes in soil. Soil Sci. Soc. of Amer. Proc. 29:328-329.

Mathis, G.W., C.C. Jaynes, and G.W. Thomas. 1965. Root development of plains bristlegrass as measured by soil placement of radiophosphorus. J. Range Manage. 18:30-33.

McClure, J.W., and C. Harvey. 1962. Use of radiophosphorus in measuring root growth of sorghums. Agron. J. 54:457-459.

Nye, P.H., and W.N.M. Foster. 1961. The relative uptake of phosphorus by crops and natural fallow from different parts of their root zone. J. Agr. Sci. 56:299-306.

Schuster, J.L. 1964. Root development of native plants under three grazing intensities. Ecology 45:63-70.

Smith, D.R. 1967. Effects of cattle grazing on a ponderosa pine-bunchgrass range in Colorado. U.S. Dep. Agr. Tech. Bull. 1371, 60 p.

\section{The University of British Columbia Department of Animal Science}

Applications are invited for the position of Assistant Professor in the Department of Animal Science, University of British Columbia. Candidates must hold the Ph.D. degree and be eligible for membership in the British Columbia Institute of Agrologists. Post-graduate training and experience in the area of beef cow nutrition is essential. Background in the animal aspects of range management, and in systems modelling, would be highly desirable.

The successful candidate will be expected to participate in the teaching of undergraduate and graduate courses, and to undertake research in the beef cattle producing areas of British Columbia. The appointment will be effective July 1, 1979.

Applications, including curriculum vitae, and the names of three referees should be sent to:

\section{Dr. B.D. Owen, Chairman \\ Department of Animal Science \\ Faculty of Agricultural Sciences \\ The University of British Columbia \\ 2075 Wesbrook Mall \\ Vancouver, British Columbia V6T 1W5.}

The University of British Columbia offers equal opportunity of employment to qualified male or female candidates.

\section{Assistant Professor}

September 1979, $\$ 14,256-\$ 17,136 /$ year, based on qualifications. Tenure on 9-month appointment. Teach resource administration, forest harvesting, resources, products, dendrology. Position includes other related duties, as student advisement. Doctorate in relevant discipline with minimum one degree in forestry. Enthusiastic undergraduate education essential. Resume, academic transcripts, 3 reference letters: Dr. Walter Mark, Chairman, Faculty Search Committee, Natural Resource Management. California Polytechnic State Univ, San Luis Obispo, Ca 93407.

Closing date is May 1, 1979.

Affirmative action/equal opportunity/title ix employer. 